\title{
CARACTERÍSTICAS COMPORTAMENTAIS EMPREENDEDORAS: EM CENA OS FUTUROS ADMINISTRADORES
}

DOI: 1014211/regepe.v5i1.277

Artigo recebido em: 04/06/2015 Artigo aprovado em: 03/03/2016

Cristiele Dal Osto Minuzzi - Faculdade Integrada de Santa Maria ${ }^{1}$ Katiuscia Schiemer Vargas - Universidade Federal do Pampa ${ }^{2}$ Camila Borges Fialho - Faculdade Integrada de Santa Maria ${ }^{3}$

Resumo: O objetivo central deste estudo consiste em investigar as Características Comportamentais Empreendedoras (CCEs) mais evidentes em discentes de um Curso Superior em Administração de uma Instituição de Ensino Superior Privada. De forma específica, pretende-se traçar o perfil dos discentes, mapear e comparar tais características empreendedoras de acordo com o gênero dos discentes. A pesquisa classifica-se, quanto aos seus objetivos, como descritiva e quantitativa quanto à abordagem do problema. Quanto aos resultados, verificou-se que as Características Comportamentais Empreendedoras do Conjunto de Realização, que estão relacionadas com o desafio pessoal e com a competição como forma de autoavaliação, foram as que mais se destacaram entre os discentes. No que se refere à relação das Características Comportamentais Empreendedoras com 0 gênero, evidencia-se o fato de que as mulheres, de forma geral, expressam as maiores médias, em oito das dez características, no entanto, não houve diferenças expressivas de média entre os gêneros.

Palavras-chave: Características Comportamentais Empreendedoras; Empreendedorismo; Administradores; Gênero.

\section{ENTREPRENEURIAL BEHAVIOURAL CHARACTERISTICS: THE FUTURE MANAGERS}

Abstract: The central aim of this study is to investigate the Entrepreneurs Behavioral Characteristics (EBCs) more evident in academicians of an Administration Higher Education School of a Private Higher Education Institution. Specifically, it intends to profile the academics, map and compare these entrepreneurial characteristics according to the genre of the academics. The research is classified, about to its goals, as descriptive and is quantitative on the approach of the problem. About the results, it was found that the Entrepreneurs Behavioral Characteristics of the Set Attainment, which are related to the personal challenge and the competition as a

\footnotetext{
1 E-mail: kakaminuzzi@gmail.com

2 Endereço:.R. Barão do Triunfo, 1048 - Centro, Santana do Livramento - RS, 97573-634 E-mail: katiuscia.schiemer@gmail.com

${ }^{3}$ E-mail: ca.fialho@yahoo.com.br
}

MINUZZI, C. D. O.; VARGAS, K. S.; FIALHO, C. B. . Características comportamentais empreendedoras: em cena os futuros administradores. Revista de Empreendedorismo e Gestão de Pequenas Empresas, v.5, n.1, 2016. 
form of self-evaluation, were the most outstanding among academics. With regard to the relationship of Entrepreneurs Behavioral Characteristics with gender, it is evident the fact that women, in general, express the highest averages, in eight of ten features, however, there was no significant mean differences between genres.

Keywords: Entrepreneurs Behavioral Characteristics; Entrepreneurship; Administrators; Gender.

\section{Introdução}

O atual cenário competitivo apresenta inúmeras ameaças e oportunidades às empresas que buscam se posicionar no mercado. Este contexto exige um posicionamento estratégico eficiente que poderá direcionar o rumo da empresa em meio às incertezas do mercado. Assim, a crescente competição que se estabelece no ambiente empresarial, traz como novo desafio o desenvolvimento de modelos de gestão que lhe garantam certo nível de competitividade.

Somada a este cenário, a globalização e os avanços da tecnologia tornam o mercado de trabalho cada vez mais exigente, o que aumenta a procura por profissionais qualificados. Busca-se pessoas capazes de compreender que o mundo está em transformação contínua e adaptar-se é gerar soluções para os desafios impostos pelo ambiente de trabalho. Um profissional bem sucedido no mercado de trabalho precisa desenvolver capacidades de agir eficazmente em determinadas situações, apoiado num conjunto de conhecimentos, habilidades e atitudes.

Este conjunto de conhecimentos, habilidades e atitudes compreendem as competências do indivíduo. As competências individuais podem ser definidas a partir de diferentes perspectivas. Na visão de Fleury e Fleury (2001), o conceito de competência deve ser pensado como um conjunto de conhecimentos, habilidades e atitudes que explicam um alto desempenho, fundamentados na inteligência e personalidade das pessoas e pode ser percebida como estoque de recursos. $\mathrm{Na}$ perspectiva de Zarifian (2001), a competência do indivíduo está relacionada a tomar iniciativa e assumir responsabilidades frente às situações profissionais que surgem.

Já Fernandes (2004), acrescenta a ideia de que a competência está relacionada à complexidade inerente ao contexto organizacional, visto que as 
pessoas que possuem maior nível de desenvolvimento, supostamente apresentam maior capacidade de abstração e competências mais elaboradas do que outras.

A demonstração das competências pode ser observada através das características e dos comportamentos individuais. Zarifian (2001) afirma que as características empreendedoras estão intimamente ligadas às competências individuais, pois o indivíduo que possui essas características no seu ambiente de trabalho é caracterizado por suas competências empreendedoras.

Oliveira e Sanabio (2005) parecem corroborar quando afirmam que para que seja possível manter competitivo nesse novo mercado de trabalho, ou abrir negócio próprio, é necessário que os indivíduos desenvolvam em sua personalidade uma nova característica: a empreendedora.

De acordo com Filion (1999a), os empreendedores têm visões, cuja elaboração demanda tempo, comprometimento e imaginação sobre o objetivo a ser perseguido e os caminhos necessários para realizá-lo. O empreendedor está voltado para a definição de contextos e a organização dos recursos necessários para fazer frente às oportunidades e ameaças ambientais. Um empreendedor de sucesso deve possuir características extras, além de alguns atributos pessoais que, somados às características sociológicas e ambientais, os tornam excepcionais (DORNELAS, 2005).

Neste cenário, se inserem os futuros administradores, hoje discentes do Curso de Administração, os quais necessitam cada vez mais desenvolver características empreendedoras para que possam competir nesse ambiente de agressiva concorrência.

Diante destas necessidades e da atual dinamicidade do mercado, o mundo corporativo vem exigindo profissionais flexíveis, sensíveis e cooperativos. Essas características, bem como as características empreendedoras, podem se expressar diferentemente entre homens e mulheres, devido às suas distinções naturais. Homens e mulheres passam por experiências distintas desde a infância e isto pode influenciar na sua formação e características enquanto administradores.

Segundo Frankel (2007), as mulheres são naturalmente líderes e certas características exclusivas delas podem fazer a diferença no novo conceito de liderança que as empresas buscam atualmente. Por outro lado, reconhece-se 
também o estilo de gestão masculino que, na maioria das vezes, parece mais adequado para situações de chefia e controle. Assim, há a ideia de diferenciação das características e competências de gestão levando em consideração a variável gênero.

O principal desafio enfrentado por homens e mulheres empreendedores tem sido a necessidade de se tornarem mais flexíveis e adaptáveis às características do ambiente de negócios. Observam-se empresas formadas por indivíduos carentes de habilidades, de acordo com as suas características individuais que diferem de gênero para gênero, que podem ser consideradas necessárias para garantir o aumento do tempo de vida da empresa.

A partir do exposto, emerge o objetivo central da pesquisa: investigar as Características Comportamentais Empreendedoras (CCEs) mais evidentes em discentes de um Curso Superior em Administração de uma Instituição de Ensino Superior Privada (IES). Em específico, pretende-se traçar o perfil dos discentes, mapear e comparar tais características empreendedoras de acordo com o gênero deles.

\section{Empreendedorismo}

O início dos primeiros estudos sobre empreendedorismo se deu no século XVII e a teoria passou a se desenvolver até os dias atuais. Existem vários estudos que buscam aprofundar o conceito de empreendedorismo em uma tentativa de abranger todos os campos científicos da atualidade. Segundo Hisrich e Peters (2004), o empreendedorismo é um processo dinâmico em que o indivíduo cria algo que tenha valor para a sociedade. Para isso, é necessário dedicar tempo, esforço e correr riscos (financeiros, psíquicos e sociais) correspondentes e, consequentemente, obter recompensas de satisfação e independência econômica e pessoal.

O pioneiro na definição do que é um empreendedor foi Joseph Alois Schumpeter, no início do século XX, quando caracterizou o empreendedor como aquele que inova, que insere novos produtos e serviços por meio da criação de 
novas formas de organização, ou ainda, pela exploração de novos recursos e materiais (SCHUMPETER, 1997).

Para Filion (1999b), o empreendedor é uma pessoa criativa, marcada pela capacidade de estabelecer e atingir objetivos, uma pessoa que mantém alto nível de consciência no ambiente em que vive, usando-a para detectar oportunidades de negócios e inovação constante.

Já Dornelas (2003), quando trata de empreendedorismo corporativo, destaca que é um processo pelo qual um indivíduo ou um grupo de indivíduos, associados a uma organização existente, cria uma nova organização ou instigam a renovação ou inovação dentro da organização existente.

Algumas pessoas desenvolvem características empreendedoras próprias que podem ser propulsoras para a realização profissional, porém qualquer indivíduo pode tornar-se um empreendedor se receber orientações e uma preparação correta. Conhecer as atitudes, a forma de agir e pensar dessas pessoas em diferentes ambientes e situações tornou-se essencial para 0 desenvolvimento do empreendedorismo.

Com relação ao desenvolvimento do empreendedorismo, a pesquisa realizada pelo Global Entrepreneurship Monitor (GEM), em 2012, indicou o empreendedorismo como principal fator de desenvolvimento econômico de um país e fez recomendações a países que buscam o desenvolvimento econômico. Em uma análise atual, a pesquisa revelou que a proporção dos brasileiros que deseja ter o próprio negócio é superior a dos que desejam fazer carreira em empresas. O Brasil aparece em quarto lugar num total de 67 países em termos de número de empreendedores. Em 2012, 30,2\% da população adulta, entre 18 e 64 anos, estavam envolvidos na criação ou administração de um negócio. Entre 2002 e 2012, essa taxa apresentou um aumento de $44 \%$ (saindo de 20,9\% para $30,2 \%$ ) (GEM, 2012).

Os resultados da pesquisa GEM confirmam que o empreendedorismo é importante para a prosperidade econômica de um país e que as baixas taxas de criação de novas empresas conduzem à estagnação econômica e à diminuição significativa da competitividade. 
As funções empreendedoras que foram conceituadas desde a abordagem clássica pelos atos de planejar, organizar, dirigir e controlar possuem muitas similaridades, porém o diferencial visionário é característico dos empreendedores. Filion (1999b) afirma que uma das grandes diferenças entre o empreendedor e as pessoas que trabalham em organizações é que o empreendedor define o objeto que vai determinar seu próprio futuro.

Um administrador possuir ou desenvolver características empreendedoras pode lhe permitir uma visão de futuro para planejar o presente. Contudo, nem todos os administradores serão empreendedores, visto que o empreendedor precisa ter consigo, pessoas com características diversas que the permitam enriquecer sua equipe e garantir diferentes visões estratégicas. Através de atitudes inovadoras, o empreendedorismo permite que a empresa se mantenha competitiva no mercado de trabalho.

A presença do empreendedor torna-se cada vez mais fundamental para as organizações, quando avaliada a necessidade cotidiana de criatividade, do trabalho eficiente, da inserção de novas possibilidades e da criação de uma nova postura de trabalho. Os empreendedores são componentes essenciais para mobilizar capital, agregar valor aos recursos naturais, produzir bens e controlar os meios para administrar o comércio.

Os empreendedores se formam a partir de competências inerentes a esse indivíduo. Assim, torna-se relevante entender e definir os estudos em competências. Deste modo, aborda-se a seguir o mapa dos estudos em competências.

\section{Características Empreendedoras}

As características empreendedoras denotam as principais atitudes que os empreendedores exteriorizam no desempenho das suas funções. Existem vários autores e abordagens que definem as características empreendedoras, entretanto, elas normalmente são complementares e não conflitantes.

As características empreendedoras são traços da personalidade, atitudes e comportamentos que contribuem para alcançar o êxito nos negócios (DOLABELA, 
1999). Já Zarifian (2001) assegura que as características empreendedoras estão intimamente ligadas às competências empreendedoras, pois o indivíduo que possui essas características no seu ambiente de trabalho é caracterizado por suas competências empreendedoras. Assim, entende-se que as competências podem estar associadas a atitudes empreendedoras e vinculadas ao senso de identificação de oportunidades dentro da organização.

Em síntese a respeito das características do empreendedor, Venturi e Lenzi (2003) afirmam que são pessoas que possuem maior comprometimento, determinação e perseverança, são guiadas pela autorrealização e crescimento, possuem senso de oportunidade e orientação por metas, assumem responsabilidades, são persistentes na resolução de problemas, são realistas com senso de humor, buscam obter feedback, assumem riscos calculados, sabem lidar com o fracasso e são formadores de equipes.

Dentre muitos autores que estudaram o comportamento empreendedor, David McClelland destacou-se por uma pesquisa realizada em 34 países, a partir de 1982, identificando uma dezena de características de comportamento empreendedor, comuns às pessoas vitoriosas.

McClelland (1961), que dedicou sua vida ao estudo dos empreendedores e suas características, afirma que uma pessoa empreendedora é aquela que utiliza com certa frequência e certa intensidade as CCEs (Características Comportamentais Empreendedoras), estando imbuído da convicção do papel destas pessoas no desenvolvimento das nações.

De acordo com McClelland (1961), o sucesso empresarial não consiste apenas no desenvolvimento de habilidades específicas, tais como finanças, marketing e produção, mas também das habilidades atitudinais empreendedoras, através do aperfeiçoamento de tais características. Segundo ele, o indivíduo empreendedor tem uma estrutura motivacional diferenciada pela presença marcante de uma necessidade de realização, que o impele a buscar objetivos que envolvem atividades desafiantes e que não são determinados apenas pelas possíveis recompensas em prestígio e dinheiro.

Segundo Lenzi (2002), as pesquisas de McClelland (1961) identificaram três conjuntos de características empreendedoras: conjunto de realização, de 
planejamento e de poder. A busca de oportunidades e iniciativa, correr riscos calculados, exigência de qualidade e eficiência, persistência e comprometimento, formam o conjunto de realização, enquanto que a busca de informações, estabelecimento de metas, planejamento e monitoramento sistemático compõem o conjunto de planejamento. Em relação ao conjunto de poder, as características inseridas foram a persuasão e rede de contatos, a independência e autoconfiança.

As características que o empreendedor bem-sucedido deve possuir, desenvolver ou apenas aprimorar e seus três comportamentos característicos fazem parte dos conjuntos das denominadas Características Comportamentais Empreendedoras (CCEs), de acordo com os estudos realizados por McClelland (1961).

Cada uma das dez CCEs está inserida em um dos três comportamentos característicos do empreendedor identificados por McClelland (1961) e apresentadas na Figura 1.

\section{FIGURA 1 - CONJUNTO DE CARACTERÍSTICAS COMPORTAMENTAIS EMPREENDEDORAS}

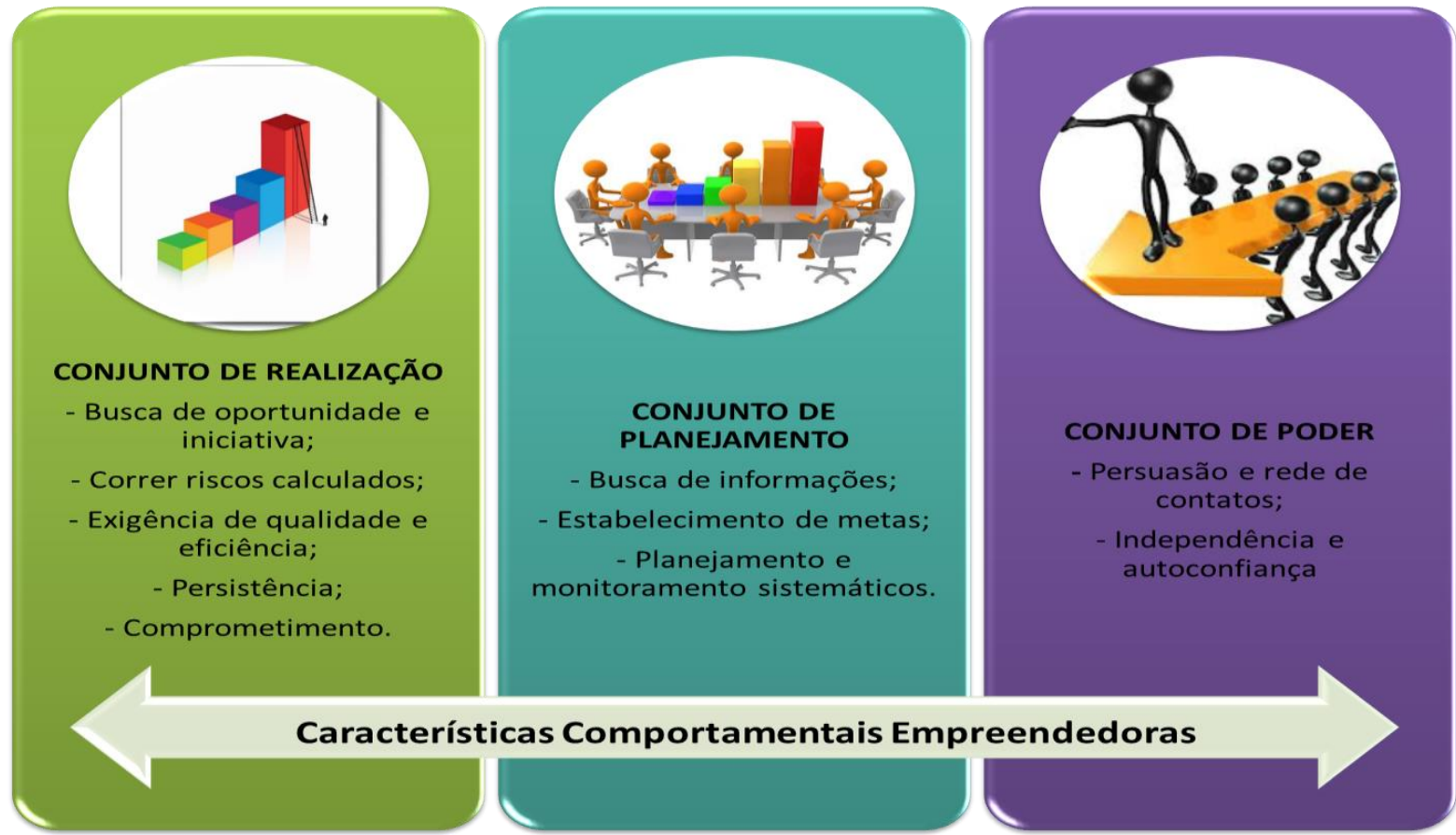

FONTE: Elaborada pelos autores com base em McClelland (1961).

Tais características devem ser exercidas de forma sensata e estar presentes no empreendedor, sendo que essas características o fazem um indivíduo especial,

MINUZZI, C. D. O.; VARGAS, K. S.; FIALHO, C. B. . Características comportamentais empreendedoras: em cena os futuros administradores. Revista de Empreendedorismo e Gestão de Pequenas Empresas, v.5, n.1, 2016. 
na medida em que este tem visão de futuro e é potencial transformador da sociedade.

As características do conjunto de realização estão relacionadas com 0 desafio pessoal, a competição como forma de autoavaliação, sendo elas:

- Busca de oportunidade e iniciativa: o indivíduo faz as coisas antes de ter sido solicitado ou antes de ser forçado pelas circunstâncias; expande os negócios para novas áreas de atuação; aproveita realmente as oportunidades que surgem;

- Correr riscos calculados: avalia e discute as alternativas; procura manter sempre o controle da situação para reduzir os riscos; se envolve em situações de riscos moderados;

- Exigência de qualidade e eficiência: procura novas formas de fazer melhor as coisas, de fazer mais rápido ou mais barato; faz as coisas de forma que supere os padrões de excelência; assegura que o seu trabalho será feito no tempo e com a qualidade combinada;

- Persistência: enfrenta os desafios das mais variadas formas e quantas vezes forem necessárias para superar os obstáculos;

- Comprometimento: sacrifica-se e faz qualquer esforço para completar uma tarefa; está sempre colaborando com os empregados para que o trabalho seja terminado; faz qualquer coisa para manter seu cliente.

No conjunto de planejamento, as Características Comportamentais Empreendedoras estão relacionadas ao modo como se planeja fazer determinado trabalho, sendo elas:

- Busca de informações: procura pessoalmente todas as informações possíveis sobre o ambiente em que está inserido; busca auxílio de especialistas para obtenção de assessoria técnica ou comercial;

- Estabelecimento de metas: os objetivos e metas são desafiantes e tem um significado pessoal; as metas são claras, objetivas e definidas a longo prazo; as metas estabelecidas a curto prazo são mensuráveis;

- Planejamento e monitoramento sistemáticos: divide as tarefas de grande porte em sub tarefas com prazos definidos; está sempre revisando 
os seus planos, observando as diversas variáveis que possam influenciar; faz uso de registros financeiros para a tomada de decisões.

Já o conjunto de poder apresenta as Características Comportamentais Empreendedoras referentes à influência exercida sobre as pessoas, o poder de mudar a opinião, sendo elas:

- Persuasão e rede de contatos: discute estratégias antecipadamente para influenciar e persuadir os outros; utiliza-se de pessoas-chave para atingir os próprios objetivos; está sempre desenvolvendo e mantendo relações comerciais;

- Independência e autoconfiança: busca autonomia sobre normas e controles de outros; mesmo diante de resultados adversos mantém seu ponto de vista; demonstra confiança de sua própria capacidade.

A necessidade de realização é a primeira das necessidades identificadas dentre os empreendedores bem-sucedidos. Essas pessoas estabelecem metas em suas vidas e comprometem-se com elas. Por buscarem continuamente a realização, desenvolvem comportamentos que as levam ao sucesso.

\section{Procedimentos Metodológicos}

Objetivando analisar as Características Comportamentais Empreendedoras (CCEs) mais evidentes em discentes de um Curso Superior em Administração, apresenta-se, neste tópico, a estrutura metodológica a ser adotada na pesquisa. Para melhor compreensão, optou-se por apresentá-la em três partes: tipo de pesquisa; população e amostra; e coleta e análise dos dados.

\section{Tipo de Pesquisa}

Buscando alcançar os objetivos propostos, adotou-se um plano de pesquisa de caráter descritivo, com uma abordagem quantitativa, utilizando-se de uma survey.

Conforme Gil (2002), a pesquisa descritiva tem por objetivo descrever as características de determinada população ou fenômeno e o estabelecimento de 
relações entre as variáveis, envolvendo a utilização de técnicas padronizadas de coleta de dados, como questionário e observação sistemática.

A abordagem quantitativa é recomendada para o estudo de grandes aglomerados de dados e de conjuntos demográficos. Deste modo, tem maior aplicabilidade no levantamento do perfil de determinada população, na identificação do grau de conhecimento e opiniões, bem como hábitos e comportamentos (MINAYO; SANCHES, 1993).

A pesquisa survey pode ser descrita como a obtenção de dados ou informações sobre características, ações ou opiniões de um determinado grupo de pessoas, indicado como representante de uma população alvo, por meio de um instrumento, normalmente um questionário (TANUR, 1993 apud PINSONNEAULT; KRAEMER, 1993).

\section{População e Amostra}

A população-alvo de uma pesquisa corresponde à coleção de elementos que possuem a informação procurada pelo pesquisador e sobre os quais devem ser feitas inferências (MALHOTRA, 2006).

Para a presente pesquisa, tomou-se como população-alvo, discentes de um Curso Superior em Administração de uma IES privada. No momento de realização da pesquisa, havia 252 discentes matriculados no curso. Baseando-se no número total de discentes, calculou-se a amostra da pesquisa.

De acordo com Marconi e Lakatos (2003), amostra é uma parcela convenientemente selecionada do universo, um subconjunto do universo. Para o estudo, utilizou-se a técnica de amostragem por conveniência, selecionando os sujeitos que participariam da pesquisa (MALHOTRA, 2006), uma vez que a coleta iniciou com as turmas de discentes mais avançadas no Curso. Assim, para definir a amostra mínima da presente pesquisa, considerou-se um nível de confiança de $95 \%$ e um erro padrão de $5 \%$, a partir da seguinte fórmula: 


$$
n=\frac{Z_{\alpha / 2}^{2} \cdot \hat{p} \cdot \hat{q} \cdot N}{e^{2}(N-1)+Z_{\alpha / 2}^{2} \cdot \hat{p} \cdot \hat{q} \cdot N}
$$

Onde:

$\mathrm{p}=$ percentual estimado

$\mathrm{e}=$ erro amostral

n= População

Para o cálculo da amostra, admitiu-se o valor $p=0,5$, uma vez que não é possível estimar o número de casos similares ao estudado, ou seja, conhecer o número de instituições com discentes em Cursos de Administração em condições próximas ao caso apresentado. Ainda, a utilização do percentual estimado $p=0,5$ resulta em um maior tamanho da amostra.

A partir do cálculo definiu-se uma amostra mínima de 152 discentes. Participaram da pesquisa, os discentes desta IES privada que aceitaram, voluntariamente, responder ao questionário. Destaca-se que o número de respondentes definido na amostra mínima foi igual ao número de participantes do estudo, perfazendo $60,3 \%$ da população estudada. Ressalta-se que os discentes foram considerados, nesta pesquisa, como futuros administradores e/ou empreendedores.

\section{Coleta e Análise dos Dados}

A coleta de dados é a fase da pesquisa em que se entra em contato com as informações para registrar os dados que a definirão (BARQUETTE; CHAOUBAH, 2007). A coleta de dados ocorreu mediante a aplicação de questionários e posterior análise e discussão.

O questionário utilizado nesta pesquisa é formado por um conjunto de 65 questões, sendo dividido em duas partes. A primeira parte possui 10 questões mistas sobre o perfil do pesquisado como, por exemplo, questões relacionadas à idade, gênero, escolaridade, se trabalha e/ou realiza estágio. A segunda parte é baseada nas dez Características Comportamentais Empreendedoras de McClelland 
(1972), composta por 55 afirmações. Cada uma delas foi respondida de acordo com uma escala de 5 pontos, correspondendo a seguinte gradação: $1=$ nunca, 2 = raras vezes, 3 = algumas vezes, 4 = usualmente e 5 = sempre.

De acordo com o Quadro 1, as dez Características Comportamentais Empreendedoras (CCEs) dividem-se em três conjuntos: Conjunto de Realização, Conjunto de Planejamento e Conjunto de Poder. Cada uma delas é identificada por cinco questões do questionário, conforme segue:

\section{QUADRO 1 - COMPILAÇÃO DAS CCES}

\begin{tabular}{|c|l|c|}
$\begin{array}{c}\text { Conjunto das Características } \\
\text { Empreendedoras }\end{array}$ & \multicolumn{1}{|c|}{$\begin{array}{c}\text { Características Comportamentais } \\
\text { Empreendedoras }\end{array}$} & \multicolumn{1}{c|}{ Questões } \\
\hline \multirow{4}{*}{\begin{tabular}{c} 
Conjunto de Realização \\
\cline { 2 - 3 }
\end{tabular}} & Busca de oportunidade e iniciativa & $1,12,23,34,45$. \\
\cline { 2 - 3 } & Persistência & $2,13,24,35,46$. \\
\cline { 2 - 3 } & Comprometimento & $3,14,25,36,47$. \\
\cline { 2 - 3 } & Exigência de qualidade e eficiência & $4,15,26,37,48$. \\
\cline { 2 - 3 } & Correr riscos calculados & $5,16,27,38,49$. \\
\hline \multirow{2}{*}{ Conjunto de Planejamento } & Estabelecimento de metas & $6,17,28,39,50$. \\
\cline { 2 - 3 } & Busca de informações & $7,18,29,40,51$. \\
\cline { 2 - 3 } & Planejamento e monitoramento sistemáticos & $8,19,30,41,52$. \\
\hline Conjunto de Poder & Persuasão e rede de contatos & $9,20,31,42,53$. \\
\cline { 2 - 3 } & Independência e autoconfiança & $10,21,32,43,54$. \\
\hline
\end{tabular}

FONTE: Os autores (2016).

O instrumento utilizado para a coleta dos dados é deveras extenso, uma vez que fora aplicado em ambiente acadêmico (sala de aula). No entanto, os pesquisadores julgaram ser o modo mais correto para a coleta dos dados, pois o estudo está relacionado ao conjunto de características empreendedoras - discentes - futuros empreendedores. Neste sentido, foi necessária a sensibilização dos discentes para o engajamento na pesquisa, por meio da explicação do objetivo do estudo.

Após organizado, o questionário precisa ser testado antes de sua utilização definitiva, ou seja, é necessário que passe por um pré-teste. Segundo Marconi e Lakatos (2003), o pré-teste pode ser feito aplicando alguns exemplares em uma pequena população escolhida, com isso evidenciará possíveis falhas existentes. Neste sentido, foram distribuídos 10 questionários entre os professores da IES privada, 8 questionários foram respondidos e serviram como teste ativo inicial e como etapa de finalização das questões e do formato do questionário. O pré-teste foi realizado com os docentes com o objetivo de não eliminar discentes respondentes,

MINUZZI, C. D. O.; VARGAS, K. S.; FIALHO, C. B. . Características comportamentais empreendedoras: em cena os futuros administradores. Revista de Empreendedorismo e Gestão de Pequenas Empresas, v.5, n.1, 2016. 
uma vez que teriam acesso prévio ao questionário. Os pesquisadores optaram pela participação dos docentes no pré-teste pelo conhecimento do perfil dos alunos, o que contribuiu para o alinhamento da versão final do instrumento.

Para a análise, os dados foram tabulados com a utilização do Microsoft Office Excel® e, posteriormente, realizadas as análises estatísticas através dos resultados obtidos pelo programa SPSS, tais como: frequência, média e teste T para amostras independentes.

\section{Resultados e Discussões}

Nesta etapa do trabalho, realiza-se a análise e discussão dos resultados, apurados após a aplicação dos questionários aos discentes da IES privada pesquisada, sendo descritos no intuito de responder os objetivos inicialmente estabelecidos no estudo.

É importante evidenciar que os dados obtidos na coleta, por meio do questionário de McClelland (1972), tem metodologia própria de cálculo, no qual busca-se mensurar as ocorrências comportamentais e evitar uma autoavaliação exageradamente condescendente.

\section{Perfil dos Pesquisados}

$\mathrm{Na}$ apresentação das características socioeconômicas, busca-se atender ao primeiro objetivo específico, ou seja, traçar o perfil dos discentes de uma IES privada.

A pesquisa evidenciou que a maioria dos discentes respondentes pertence ao sexo feminino, 55,3\%; a faixa etária predominante é de 21 a 25 anos, equivalendo a 40,1\%; $24,3 \%$ dos respondentes encontram-se na faixa etária de 26 a 30 anos; 13,2\% e 11,2\% correspondem respectivamente a faixa etária entre 16 e 20 anos e entre 31 e 35 anos. Vale ressaltar que as faixas etárias com menor percentual foram as de 36 a 40 anos e acima de 40 anos, com percentuais de $4,6 \%$ e de $6,6 \%$ dos pesquisados, respectivamente. 
Constatou-se, ainda, que a maioria dos discentes respondentes trabalha e/ou realiza estágio concomitantemente com a faculdade, correspondendo a 87,5\%. Dos 133 discentes que trabalham e/ou realizam estágio, 59,2\% estão em alguma empresa inserida no mercado há mais de 10 anos; enquanto que 15,8\% trabalha e/ou realiza estágio em alguma empresa que está no mercado entre 5 e 10 anos; e $14,5 \%$ está em alguma empresa que está no mercado em até 5 anos.

Delimitam-se assim, informações que contribuirão para o desenvolvimento das análises e comparações que serão abordadas nos tópicos seguintes.

\section{Características Comportamentais Empreendedoras (CCEs)}

As dez Características Comportamentais Empreendedoras (CCEs) dividemse em três conjuntos: Conjunto de Realização, Conjunto de Planejamento e Conjunto de Poder. Cada uma delas é identificada por cinco questões do questionário desenvolvido por McClelland (1972).

Conforme a análise dos resultados das CCEs dos discentes, constatou-se que, de forma geral, os respondentes possuem tais características, pois a média total foi de $\bar{x}=3,67$. O Conjunto de Realização foi o que atingiu maior média, com o valor de $\bar{x}=3,76$, enquanto que a média do Conjunto de Planejamento foi de 3,69 e o Conjunto de Poder obteve a média de $\bar{x}=3,56$. A Figura 2 ilustra as médias dos referidos conjuntos com as suas respectivas Características Comportamentais Empreendedoras: 
FIGURA 2 - MÉDIAS DOS CONJUNTOS DE REALIZAÇÃO, PLANEJAMENTO E PODER

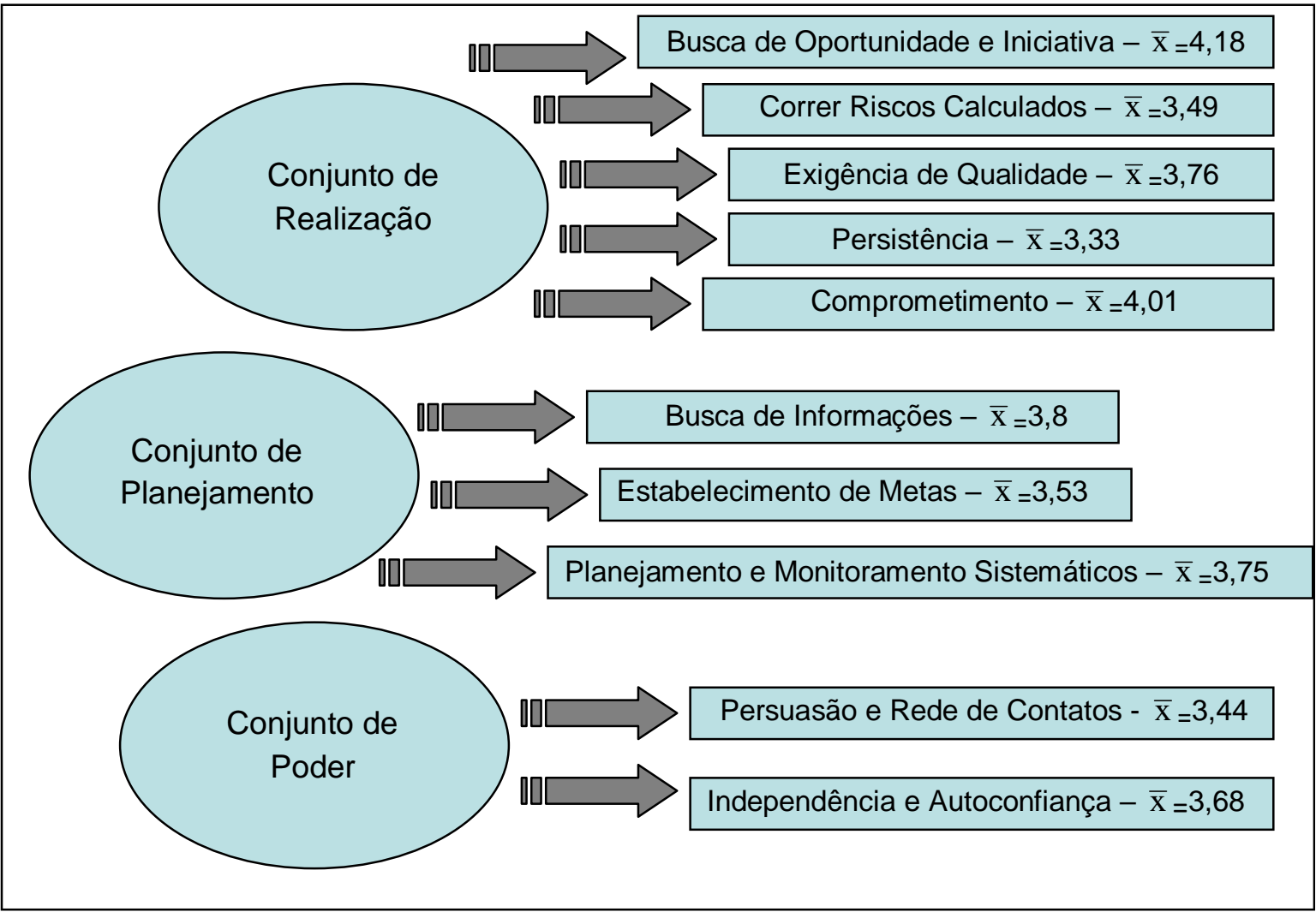

FONTE: Os autores (2016).

A Característica Comportamental Empreendedora "Busca de Oportunidade e Iniciativa" obteve a maior média, representando $\bar{x}=4,18$, demonstrando que os pesquisados são pró-ativos, fazem as coisas antes de serem solicitados ou antes de serem forçados pelas circunstâncias, gostam de desafios e sabem aproveitar as oportunidades que surgem.

Além disso, verificou-se que a característica "Comprometimento" foi a segunda média acentuada, com $\bar{x}=4,01$, fato que revela haver grande esforço na hora de completar uma tarefa, fazendo qualquer coisa para manter o cliente.

Nessa mesma perspectiva, os discentes respondentes obtiveram uma média de $\bar{x}=3,8$ para a característica "Busca de Informações", que está inserida no Conjunto de Planejamento, assegurando que a maioria dos discentes procura pessoalmente todas as informações possíveis sobre o ambiente em que está inserida. Mesmo assim, pode-se inferir que as CCEs com maior destaque, estão inseridas no Conjunto de Realização.

MINUZZI, C. D. O.; VARGAS, K. S.; FIALHO, C. B. . Características comportamentais empreendedoras: em cena os futuros administradores. Revista de Empreendedorismo e Gestão de Pequenas Empresas, v.5, n.1, 2016. 
Constatou-se, ainda, o fato de que as médias das CCEs enquadraram-se nos três conjuntos, demonstrando várias características relacionadas à realização, planejamento e poder. No entanto, pode-se ressaltar que a média mais baixa pertence, assim como a média mais alta, ao Conjunto de Realização, representando $\overline{\mathrm{x}}=3,33$ para a característica "Persistência". Desse modo, evidencia-se que uma grande parte dos pesquisados não se preocupam em enfrentar os desafios impostos para superar algum obstáculo.

A Tabela 1 elenca as médias das CCEs, encontradas na pesquisa.

TABELA 1 - MÉDIA DAS CCES

\begin{tabular}{l|c}
\hline \multicolumn{1}{c}{ CCEs } & Média \\
\hline Busca de oportunidade e iniciativa & 4,18 \\
\hline Comprometimento & 4,01 \\
\hline Busca de informações & 3,8 \\
\hline Exigência de qualidade e eficiência & 3,76 \\
\hline Planejamento e monitoramento sistemáticos & 3,75 \\
\hline Independência e autoconfiança & 3,68 \\
\hline Estabelecimento de metas & 3,53 \\
\hline Correr riscos calculados & 3,49 \\
\hline Persuasão e rede de contatos & 3,44 \\
\hline Persistência & 3,33 \\
\hline
\end{tabular}

FONTE: Os autores (2016).

A partir da identificação das Características Comportamentais Empreendedoras (CCEs) dos discentes, demarcam-se as informações para o tópico seguinte, onde são feitas as comparações entre os gêneros.

\section{Comparação das Características Comportamentais Empreendedoras entre Gêneros (masculino e feminino)}

Levando em consideração a variável gênero, se insere a ideia de que as características empreendedoras podem se expressar de diferentes maneiras, devido às distinções naturais existentes em homens e mulheres, o que pode influenciar suas características enquanto futuros administradores.

Conforme comparação dos resultados das CCEs dos discentes, constatouse que, de forma geral, as mulheres apresentam as maiores médias em oito das dez MINUZZI, C. D. O.; VARGAS, K. S.; FIALHO, C. B. . Características comportamentais empreendedoras: em cena os futuros administradores. Revista de Empreendedorismo e Gestão de Pequenas Empresas, v.5, n.1, 2016. 
características, quais sejam: "Busca de Oportunidade e Iniciativa", "Exigência de Qualidade e Eficiência", "Persistência", "Comprometimento", "Busca de Informações", "Estabelecimento de Metas", "Planejamento e Monitoramento Sistemáticos", "Persuasão e Rede de Contatos".

No entanto, vale ressaltar que os homens apresentam maiores médias em duas características, Correr riscos calculados e Independência e autoconfiança, pertencentes ao Conjunto de Realização e ao Conjunto de Poder, respectivamente. Desse modo, evidencia-se que os homens procuram manter o controle da situação para reduzir os riscos e demonstram confiança de sua própria capacidade.

Os três conjuntos apresentaram as maiores médias para as mulheres, no entanto não houve diferenças significativas de média entre os gêneros. No Conjunto de Realização, a média foi de $\bar{x}=3,77$ para as mulheres, enquanto que para os homens, a média foi de $\bar{x}=\mathbf{3 , 7 3}$, existindo uma diferença de apenas 0,4 na média geral do conjunto. A característica Busca de Oportunidade e Iniciativa destacou-se dentro do referido conjunto, alcançando a média de $\bar{x}=4,20$ para as mulheres e $\bar{x}=\mathbf{4 , 1 5}$ para os homens, o que demonstra que os indivíduos se aventuram e assumem riscos.

No Conjunto de Planejamento, a diferença entre as médias dos gêneros foi consideravelmente mais expressiva, representando os valores de $\bar{x}=3,73$ para as mulheres e $\bar{x}=3,64$ para os homens, equivalendo a 0,9 de diferença na média geral. Busca de Informações foi a característica de maior destaque dentro do Conjunto de Planejamento, apresentando as médias de $\bar{x}=3,83$ para as mulheres e $\overline{\mathrm{X}}=3,76$ para os homens.

Já o Conjunto de Poder apresentou uma pequena diferença nas médias entre os gêneros, 3,57 para as mulheres e 3,54 para os homens. As duas Características Comportamentais Empreendedoras que formam esse conjunto dividiram-se da seguinte forma: Persuasão e Rede de Contatos obteve a maior média para as mulheres e Independência e Autoconfiança obteve a maior média para os homens, representando as médias de $\bar{x}=3,48$ para as mulheres e $\bar{x}=3,39$ para os homens, e $\bar{x}=3,70$ para os homens e $\bar{x}=3,67$ para as mulheres, respectivamente.

MINUZZI, C. D. O.; VARGAS, K. S.; FIALHO, C. B. . Características comportamentais empreendedoras: em cena os futuros administradores. Revista de Empreendedorismo e Gestão de Pequenas Empresas, v.5, n.1, 2016. 
Diante do exposto, verifica-se que os resultados encontrados são corroborados pela ideia de Frankel (2007) que afirma que todas as mulheres são naturalmente líderes e certas características exclusivas das mulheres podem fazer a diferença. Porém, corrobora com Machado (2008) quando revela que o empreendedorismo não é privilégio de nenhum dos gêneros, masculino ou feminino, pois ambos demonstram competências empreendedoras, seja por oportunidade ou por necessidade.

\section{Considerações Finais}

Os discentes do Curso de Administração, considerados aqui como futuros administradores, necessitam desenvolver características empreendedoras para que possam competir no mercado atual, onde o principal desafio é a necessidade de profissionais flexíveis e adaptáveis ao ambiente de negócios. Essas características podem se diferenciar de gênero para gênero. Filion (1991) afirma que o empreendedorismo é fruto de herança genética, porém é possível que as pessoas aprendam a ser empreendedores.

Diante do contexto apresentado e considerando a importância do empreendedorismo para o desenvolvimento das organizações, o trabalho teve como objetivo central investigar as características comportamentais empreendedoras mais evidentes em discentes de um Curso de Administração de uma Instituição de Ensino Superior Privada. Sendo assim, foi possível perceber que as características do Conjunto de Realização, que estão relacionadas com o desafio pessoal e com a competição como forma de autoavaliação, foram as que mais se destacaram entre os discentes.

Em relação aos objetivos específicos, foi possível identificar o perfil socioeconômico dos discentes, sendo que a maioria são mulheres e possuem idade entre 21 e 25 anos. Destaca-se também, que a maioria dos discentes respondentes da pesquisa trabalha e/ou realiza estágio concomitantemente com a faculdade. Quanto à relação das Características Comportamentais Empreendedoras (CCEs) com o gênero, evidencia-se o fato de que as mulheres, de forma geral, expressam 
as maiores médias em oito das dez características. No entanto, é preciso afirmar que não houve diferenças expressivas de média entre os gêneros.

Uma das principais limitações do presente estudo está relacionada à resistência por parte dos discentes em responder em sua totalidade o questionário aplicado, pois trata-se de um questionário extenso, contendo 65 questões.

Os resultados obtidos revelam o êxito quanto à escolha deste tema para o estudo das características empreendedoras evidenciadas entre os discentes e contribuem com informações úteis para a instituição pesquisada, que poderá utilizála para uma melhor condução do processo ensino-aprendizagem do Curso de Administração.

Por fim, sugere-se a aplicação da pesquisa a outros Cursos de Administração de outras Instituições de Ensino Superior, para que seja possível estabelecer uma comparação entre os resultados obtidos.

\section{Referências:}

BARQUETTE, S.; CHAOUBAH, A. Pesquisa de marketing. São Paulo: Saraiva, 2007.

DOLABELA, F. O segredo de Luísa. São Paulo: Cultura, 1999.

DORNELAS, J. C. A. Empreendedorismo corporativo: como ser empreendedor, inovador e se diferenciar na sua empresa. Rio de Janeiro: Campus; Elsevier, 2003.

ed. Rio de Janeiro, 2005.

Empreendedorismo: transformando idéias em negócios. 2.

FERNANDES, B. H. R. Competências e Performances Organizacionais: Um estudo empírico. 2004. Tese (Doutorado em Administração de Empresas) Programa de Pós-Graduação em Administração de Empresas - Faculdade de Economia, Administração e Contabilidade, Universidade de São Paulo, São Paulo, 2004.

FILION, L. J. O planejamento do seu sistema de aprendizado empresarial: identifique uma visão e avalie o seu sistema de relações. Revista de Administração de Empresas, São Paulo, v. 31, n. 3, p. 63-71, 1991.

- Diferenças entre sistemas gerenciais de empreendedores e operadores de pequenos negócios. Revista de Administração de Empresas, São Paulo, v. 39, n.4, p. 6-20, 1999a. 
Empreendedores e proprietários de pequenos negócios. Revista

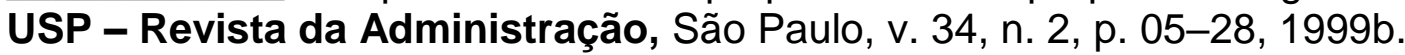

FLEURY, M. T. L.; FLEURY, A. Construindo o conceito de competência. Revista de Administração Contemporânea - RAC, v. 5, Edição Especial, p. 183-196, 2001.

FRANKEL, L. P. Mulheres lideram melhor que homens. São Paulo: Gente, 2007.

GIL, A. C. Como elaborar projetos de pesquisa. 4. ed. São Paulo: Atlas 2002.

GLOBAL ENTREPRENEURSHIP MONITOR (GEM). Empreendedorismo no Brasil. Relatório Global 2012. Disponível em: <http://www.ibqp.org.br/gem/>. Acesso em: 10 set. 2013.

HISRICH, R. D.; PETERS, M. P. Empreendedorismo. Porto Alegre: Bookman, 2004

LENZI, F. C. Perfil comparativo de empreendedores do setor de serviços: estudo em restaurantes de Balneário Camboriú. 2002. 114 f. Dissertação (Mestrado em Administração) - Centro de Ciências Sociais Aplicadas, Universidade Regional de Blumenau, Blumenau, 2002.

MACHADO, H. V. Tendências do comportamento gerencial da mulher empreendedora. In: Encontro da Anpad (EnAnpad), 32, 2008. Rio de Janeiro. Anais... Rio de Janeiro, 2008.

MALHOTRA, N. K. Pesquisa de marketing: uma orientação aplicada. 4. ed. Porto Alegre: Bookman, 2006.

MARCONI, M. A; LAKATOS, E. M. Fundamentos de metodologia científica. São Paulo: Editora Atlas, 2003.

MCCLELLAND, D. C. The achieving society. New York: VanNostrand, 1961.

A sociedade competitiva: realização e progresso social. Rio de Janeiro: Expressão e Cultura, 1972.

MINAYO, M. C. S; SANCHES, O. Quantitativo-qualitativo oposição ou complementariedade? Cad. Saúde Pública, v. 9, n. 3, p. 239-282, 1993.

PINSONNEAULT, A.; KRAEMER, K. L. Survey research in management information systems: an assessement. Journal of Management Information System, v. 10, $\mathrm{n}$. 2, p. 75-105, 1993.

SCHUMPETER, J. A. Teoria do Desenvolvimento Econômico: uma investigação sobre lucros, capital, crédito, juro e ciclo econômico. São Paulo: Nova Cultural, 1997.

MINUZZI, C. D. O.; VARGAS, K. S.; FIALHO, C. B. . Características comportamentais empreendedoras: em cena os futuros administradores. Revista de Empreendedorismo e Gestão de Pequenas Empresas, v.5, n.1, 2016. 
VENTURI, J. L.; LENZI, F. C. Desenvolvimento gerencial: da teoria acadêmica para a prática empresarial. Rio do Sul: Nova Era, 2003.

ZARIFIAN, P. Objetivo competência: por uma nova lógica. São Paulo: Atlas, 2001. 